\title{
Force Calculation by Reluctance Method in Triangular Air-Gap Magnetic System
}

\author{
Pooja Khese, Rohit Patil, Swapnil N Jani
}

\begin{abstract}
Magnetic circuit in MCCB should be reliable as Reliability is the main concern if MCCB used as the protection to the main appliances. Air-gap plays critical role in any magnetic system as increase and decrease in it will cause shift in saturation level. In this paper we are going to see the effect of air-gap variation in case of triangular air-gap. Here, Ansys software is used for magneto static analysis of the magnetic system. Relation between analytic formulation and ansys data is given by variation factor, which is used to establish force in given triangular system by just mathematical formulation. This paper will help in driving force for any triangulate air-gap system and relation between system and simulating software. Formulation of force generation is very important at design point of view as it will help in analyzing required force generation.
\end{abstract}

Keywords: About four key words or phrases in alphabetical order, separated by commas.

\section{INTRODUCTION}

Magnetic circuit is the most important part in MCCB for magnetic tripping in short circuit condition. MCCB provides protection in case of higher inrush current which causes short circuit in the system. Failure of protection can cause system damage. In case of industries in which heavy and costly appliances are used where this type of failure can cause higher cost. For magnetic system parameters which are important: saturation current, fringing flux, relative permeability and dimensions of magnetic circuit.

Magnetic circuit used in the protection system has varying air-gap size and shape. Air-gap can be in the form of square or rectangular. Designing system with proper air-gap size and shape is very important as it will directly affect the force generation in magnetic cores. As variation in air-gap will cause variation in flux linkage as given by the B-H curve, it will change the flux density and saturation level of the system. This will directly affect the force generation in the system, which is required to be created for magnetic tripping.

Specific Geometry with the magnetic core having rectangular air-gap is given by the Radoslaw Jez, Aleksander

Revised Manuscript Received on February 05, 2020.

* Correspondence Author

Pooja Khese, M. Tech, Electrical Power Systems, Institute of Technology, Nirma University, Ahmedabad, Gujarat.

Rohit Patil, Senior Design Engineer, SDDC At Larsen And Toubro Limited (E \& A), Vadodara.

Swapnil N Jani, Assistant Professor, Electrical Engineering Department, Institute of Technology, Nirma University, Ahmedabad, Gujarat.

(C) The Authors. Published by Blue Eyes Intelligence Engineering and Sciences Publication (BEIESP). This is an open access article under the CC BY-NC-ND license (http://creativecommons.org/licenses/by-nc-nd/4.0/)
Polit [1] where all the magnetic effects are considered and analyzed in COMSOL Multiphasic. Here, in this paper we

are going to derive force formula of specific system with triangular air-gap. Magnetic system required to be passed tripping test in desired magnetic band. IEC standards provide the information about the establishment of magnetic band for any magnetic system.

It is very important to analyze that the system generated force is enough for tripping the system in desired band. For tripping system in desired band some opposing force has be provided by the spring. Spring force should be enough to prevent tripping for value lesser than lower value of the band and trip reliable before the upper limit of the band.

By implementation of numerical method optimized design of a system can be prepared. In this paper numerical method for magnetic system of triangular air-gap is derived with ansys simulation.

\section{IMPLEMENTATION OF FORCE USING ANALYTICAL METHOD}

Analytical calculation is established for specific system as explain below. Here fix core of C-shape and moving core of rectangular shape creates triangular air-gap as shown below,

Source conductor is passed from the system to create flux in fixed core. This system works on electromagnetic induction principle. When current flows through the source conductor passed from fixed and moving core, creates magnetic flux generation in fix core. Flux will try to create closing path through the fix magnet, air-gap, moving magnet and will again close to the fix magnet. Here we can see approximate flux flowing path through the system.

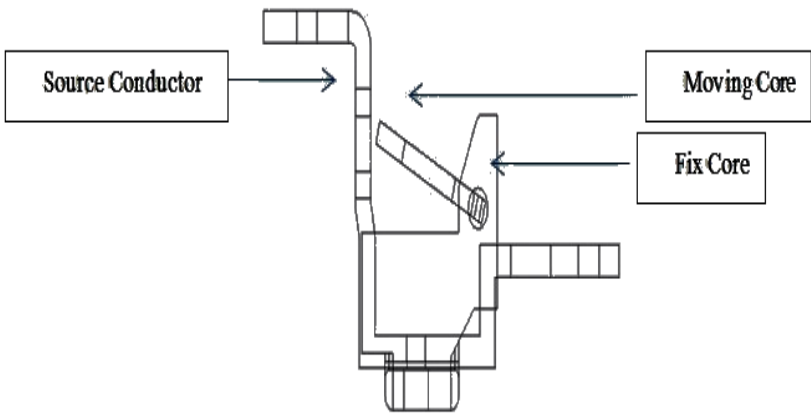

Fig. 1. Magnetic syatem

Variation in air-gap will cause change in length of flux travelling path through the air-gap. As change in air-gap will cause change in air-gap reluctance and flux density. 


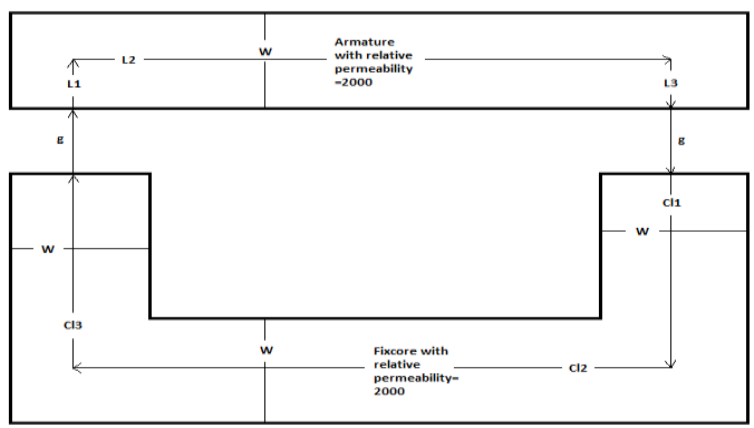

Fig. 2. Flux Travelling Path

In many literature surveys it is mentioned that it is difficult to find reluctance for triangular air-gap. Air-gap causes fringing flux effect in the system. Here, fringing flux is the flux which is not presents only at core area but also occupies the area near cross section of magnetic core. As this causes increase in area of magnetic core and causes interaction with nearby systems.

It is difficult to predict how the flux lines actually will link with the system and what path will be followed by the fringing flux. Here, in this paper we are going to derive approximate formula by considering one defined closed path of flux through the system. All the losses are considered negligible. Reluctance method is used to find the force generation in the defined system. As we know the basic formula of force:

$$
\mathrm{F}=\frac{\mathrm{S}^{2}}{2 \mu_{0} \mathrm{AgR}_{\mathrm{g}} \mathrm{R}^{2}}
$$

Where, $\mathrm{F}=$ Force in $\mathrm{N} ; \mathrm{R}=$ Reluctance in $\mathrm{AT} / \mathrm{Wb} ; \mathrm{S}=\mathrm{mmf}$ in A; $\mu=\mu_{0} \mu_{r} ; \mu_{0}=$ Relative permeability of Air $=4 \pi \times 10^{-7} ; \mu_{\mathrm{r}}=$ Relative permeability of material.

In case of triangular air-gap, length of the flux travelling path through air-gap is variable. As we travel to the depth of the system, length of flux travelling path increases. So, it is impossible to calculate reluctance of air-gap with simple formulation. Some integral form has to be established to integrate through the depth of the whole system. Here Fig.3 shows flux travelling path in triangular air-gap. Flux path varies as we move to the depth of the core. For this type of system length of the flux travelling in air-gap is changing so the effect of reluctance is also varies. Force in the air gap is also varies as the reluctance variation.

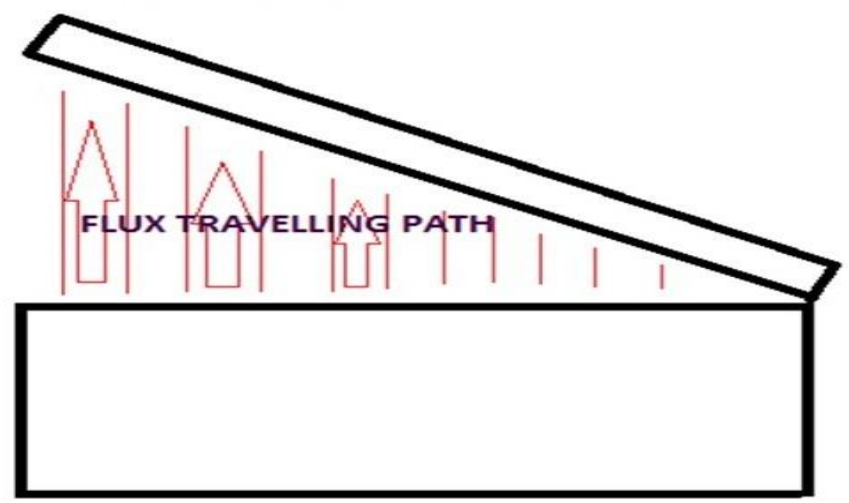

Fig. 3 Flux Through Air-gap

\section{FORMULATION OF INTEGRAL FORM}

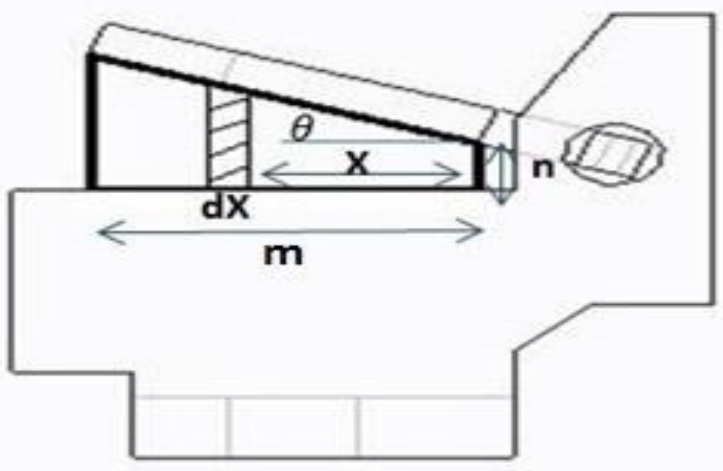

Fig. 4. Cross-section of System

Force given as,

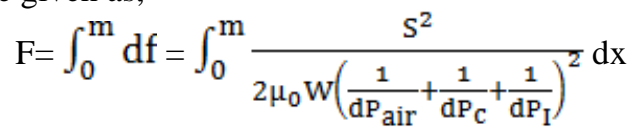

Here,

$$
\begin{gathered}
\mathrm{dP}_{\mathrm{air}}=\mu_{0}\left(\frac{\mathrm{w}}{\mathrm{n}+\mathrm{xtan} \theta}\right) \\
\mathrm{dP}_{\mathrm{c}}=\frac{\mu \mathrm{W}_{\mathrm{c}}}{\mathrm{l}_{\mathrm{c}}} \\
\mathrm{dP}_{\mathrm{I}}=\frac{\mu \mathrm{W}_{\mathrm{i}}}{\mathrm{l}_{\mathrm{i}}}
\end{gathered}
$$

Where, $\mathrm{W}=$ Thickness of material in $\mathrm{m}$; $\mathrm{P}_{\text {air }}=$ Permanence of air in $\mathrm{Wb} / \mathrm{AT}$; $\mathrm{P}_{\mathrm{c}}=$ Permanence of $\mathrm{C}$-core in $\mathrm{Wb} / \mathrm{AT}$; $\mathrm{P}_{\mathrm{I}}=$ Permanence of I-core in $\mathrm{Wb} / \mathrm{AT}$.

$$
\mathrm{F}=\int_{0}^{\mathrm{m}} \mathrm{df}=\frac{\mathrm{s}^{2}}{2 \mu_{0} \mathrm{Wa}^{2}} \int_{0}^{\mathrm{m}} \frac{1}{\left(\mathrm{x}+\frac{\mathrm{b}}{\mathrm{a}}\right)^{2}} \mathrm{dx}
$$

Where,

$$
\begin{gathered}
\mathrm{a}=\frac{\tan \theta}{\mu_{0} W} \\
\mathrm{~b}=\frac{\mathrm{l}_{\mathrm{C}}}{\mu \mathrm{W}_{\mathrm{C}}}+\frac{\mathrm{l}_{\mathrm{i}}}{\mu \mathrm{W}_{\mathrm{i}}}+\frac{\mathrm{n}}{\mu_{0} \mathrm{~W}}
\end{gathered}
$$

By using this formula approximate value of force generation can be found for system considering triangular air-gap. In this paper we are going to establish force generation for the particular system and validation with the ansys simulation.

Table- I: Dimension data of magnetic system

\begin{tabular}{|c|l|l|}
\hline $\mathrm{W}$ & Flux travelling width in air-gap & $2.5 \mathrm{~mm}$ \\
\hline $\mathrm{W}_{\mathrm{c}}$ & Flux Cutting width of fix core & $2.5 \mathrm{~mm}$ \\
\hline $\mathrm{W}_{\mathrm{i}}$ & $\begin{array}{l}\text { Width of moving core for flux } \\
\text { travelling from fix to moving core }\end{array}$ & $2.5 \mathrm{~mm}$ \\
\cline { 2 - 4 } & $\begin{array}{l}\text { Width of moving core for flux } \\
\text { travelling inside moving core }\end{array}$ & $1.5 \mathrm{~mm}$ \\
\hline $\mathrm{l}_{\mathrm{c}}$ & Flux travelling length in fix core & $\begin{array}{l}\mathrm{Cl} 1+\mathrm{Cl}+\mathrm{C} \\
13 \\
=30.4 \mathrm{~mm}\end{array}$ \\
\hline $\mathrm{l}_{\mathrm{i}}$ & $\begin{array}{l}\text { Length of flux travelling in moving } \\
\text { core from fix to moving core }\end{array}$ & $\begin{array}{l}\mathrm{L} 1+\mathrm{L} 3=1.5 \\
\mathrm{~mm}\end{array}$ \\
\hline
\end{tabular}




\begin{tabular}{|r|c|l|}
\hline & $\begin{array}{l}\text { Length of flux travelling inside moving } \\
\text { Core }\end{array}$ & $\begin{array}{l}\mathrm{L} 2=17.3 \mathrm{~m} \\
\mathrm{~m}\end{array}$ \\
\hline$\theta$ & - & $20^{\circ}$ \\
\hline $\mathrm{n}$ & - & $1.94 \mathrm{~mm}$ \\
\hline $\mathrm{m}$ & - & $9.78 \mathrm{~mm}$ \\
\hline
\end{tabular}

Here, in above table provides the dimensional data measured for magnetic system by considering travelling path as shown in Fig.2:

Constant a and b value can be calculated form equations (1) and (2),

Table- II: Calculated constant values

\begin{tabular}{|l|c|}
\hline $\mathrm{a}$ & $1.58 \times 10^{8}$ \\
\hline $\mathrm{b}$ & $6.282 \times 10^{5}$ \\
\hline
\end{tabular}

Here to define variation factor we will calculate force in given system for two current values. Here this system is established with considering all the standers. Form above mentioned data force calculated by equation (1) is given by,

$$
\mathrm{F}=\left(\mathrm{S}^{2}\right) \times\left(1.4079 \times 10^{-6}\right)
$$

where, $\mathrm{S}=\mathrm{MMF}=\mathrm{NI}$; $\mathrm{N}=1$, By putting value of different current rating in equation (4) force can be calculated for fixed triangular air-gap:

Table-III: Calculated Force for triangular air-gap

\begin{tabular}{|c|c|}
\hline \multicolumn{2}{|c|}{ Force with constant Air-Gap at angle $\mathbf{2 0}^{\mathbf{}}$} \\
\hline Current rating & Calculated force \\
\hline $1920 \mathrm{~A}$ & $5.19 \mathrm{~N}$ \\
\hline 960A & $1.297 \mathrm{~N}$ \\
\hline
\end{tabular}

Here, we can see that for constant air-gap, if the current rating is reduced to the half value than the force will reduce to the $1 / 4$ value. This validates the basic relation that for constant air-gap force is directly proposal to the square of the current .Now, in further section we are going to validate same relation in ansys simulation and establish variation factor.

\section{RESULT ANALYSIS USING ANSYS SIMULATION:}

ANSYS Workbench is software used for performing different thermal, electromagnetic and magneto static analyses. In this paper we are going to simulate magneto static analysis for described system in above section. Some required material data is provided for simulation purpose.

Table-IV: Material data

\begin{tabular}{|c|c|}
\hline Components & Material \\
\hline Source Conductor & Copper alloy \\
\hline Fix core & Mild steel \\
\hline Moving core & Mild steel \\
\hline
\end{tabular}



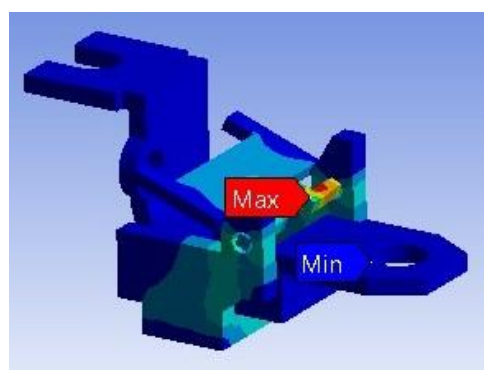

Fig.5 Ansys simulation

Here, by comparing calculated force data and ansys simulated data we can define variation factor for particular system. Here, for constant air-gap of $20^{\circ}$ variation factor is 2.2034. Variation factor is established only for given system. By this method variation factor for any system with triangular air gap can be established. Here variation factor define as,

V.F $=$ Ansys simulated force/calculated force

Table-V: Ansys simulated Force data for triangular air-gap

\begin{tabular}{|c|c|}
\hline \multicolumn{2}{|c|}{ Force with constant Air-Gap at angle $\mathbf{2 0}^{\mathbf{}}$} \\
\hline Current rating & Calculated force \\
\hline $1920 \mathrm{~A}$ & $11.436 \mathrm{~N}$ \\
\hline $960 \mathrm{~A}$ & $2.8589 \mathrm{~N}$ \\
\hline
\end{tabular}

\section{CONCLUSION}

As per the International standard IEC 60947 breaker should trip for its $80 \%$ to $120 \%$ rating. Magnetic band of breaker is developed based on this condition. To satisfy this condition force calculation is essential. Breaker should remain non-trip till its $80 \%$ of rating. Hence in this paper, system behavior is analyzed for different loading conditions and force calculation is carried out.

In this paper we have established analytical calculation for specific system and validated data by ansys simulated data. Here, we also define one variation factor for the system by which analytic and simulated values varies due to consideration of some losses. We can also define the spring opposing force required to be generated to tripping magnetic system in defined magnetic band.

This paper will help in establishing Force calculation and its variation with the simulated value. By this establishment system design will become more reliable. It provides the idea about defining dimensions of triangular air-gap. Data has been validated on actual system which shows reliable operation of the system.

\section{REFERENCES}

1. John R, et al., "Magnetic Actuators and Sensors," School of Engineering, IEEE Magnetic Society.

2. Jez R., et al., "Influence of Air-gap length and Cross-section on Magnetic Circuit Parameters," In Proceeding, COMSOL Conference, 2014, pp. 1-6.

3. Belbel E, et al., "Behavior of Switching Arc in Low-voltage Limiter Circuit Breakers," IEEE Transactions on Components, Hybrids and Manufacturing Technology, Vol. 8, Issue 1, 1985, pp. 3-12. 
4. McBride, John W et al., "Anode and Cathode Arc Root Movement during Contact Opening at High Current," IEEE Transactions on Components and Packaging Technologies, Vol. 22 Issue 1, 1999, pp. 38-46.

5. Ferree, J, et al., "Contact Blow-Apart Forces: Experience in Molded Case Circuit Breaker Contact Systems." ICEC 2014, 27th International Conference on Electrical Contacts, VDE, 2014.

6. Chen Degui, et al., "Simulation of Pressure Rise in Arc Chamber of MCCB during its Interruption Process,” Electrical Contacts 2007 Proceedings of the 53rd IEEE Holm Conference on Electrical Contacts, IEEE, 2007.

7. Yarrick, Charles J, "Arc Chute Design for Circuit Breakers," U.S. Patent No. 3,005,892, 24 October 1961

\section{AUTHORS PROFILE}

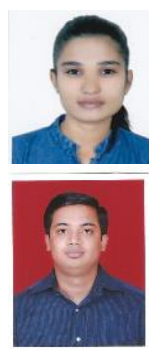

Pooja Khese is currently doing job in engineering field at Vadodara, Gujarat. She has competed her undergraduate study from Parul Institute of Technology, Vadodara and M. Tech in Electrical Power Systems from Institute of Technology, Nirma University, Ahmedabad, Gujarat.

Rohit Patil is Senior Design Engineer, SDDC at Larsen and Toubro limited (E \& A), Vadodara. He has completed his undergraduate from VJIT, Mumbai. He has an industrial experience of more than 13 years in the switchgear field.



S. N. Jani completed Bachelors in Engineering from Saurashtra University, Rajkot in June 2006 \& Masters in Technology (M.Tech.) in Electrical Engineering with specialization in Power Apparatus and Systems from Institute of Technology, Nirma University in May 2009. He has published 14 papers in various National / International Conferences has guided $15 \mathrm{M}$. Tech dissertation thesis. Currently he is working as Assistant Professor in Electrical Engineering Department, Institute of Technology, Nirma University since June 2009 and pursuing $\mathrm{PhD}$ as a Part Time Research Scholar from EE Department, School of Technology, Pandit Deendayal Petroleum University, Gandhinagar. 